\title{
Design dialogues. Ambiguity of "Design" within Architectural Studio
}

\author{
Annabel Pretty, Peter McPherson \\ Unitec Institute of Technology, New Zealand \\ School of Architecture \\ apretty@unitec.ac.nz | pmcpherson@unitec.ac.nz
}

\begin{abstract}
The ambiguous nature of the word "design" offers up a complex dialectic dialogue for the architectural studio lecturers to impart to their students. Discussing the "design", more commonly referred to as the programme or scheme, is quite a different beast to the process or design methodologies the students use to create an architectural proposition or "design". Clarity around this notion of design as both the process, in being design-led, and also as the end result, becomes a necessary task for studio lecturers to inculcate into the student body.

This paper aims to navigate through the mire/path of the design methodologies as adopted within architecture studio teaching at second year level within the Bachelor of Architectural Studies, Unitec Department of Architecture - by way of using the tried and tested notions of First Insight / Empathy, Preparation, Incubation, Illumination, Verification, with the anticipation that these are the essential tools with which to interface teaching and practice, within the context of a "live build project".

Three years' worth of case studies of large scale Interdisciplinary and collaborative "live build projects" in Christchurch in conjunction with the Festival of Transitional Architecture (FESTA) are used to demonstrate and investigate the heuristic design processes that are an integral part of a prospective architect's arsenal of skills. These case studies offered a complex window of tasks, not least that the students were designing in Auckland $1000 \mathrm{~km}$ away from the Christchurch sites, and each year posed a different set of problems and clients-related issues. Luxcity 2012 / Canterbury Tales 2013 / CityUps 2014 were the students' responses to FESTA's call to rejuvenate the city centre after the earthquakes of 2010 and $20 \mathrm{II}$, and all of which were assembled only for a 24-hour period over Labour Day Weekend.
\end{abstract}

Keywords: live build projects, studio praxis, design thinking, interdisciplinarity, collaborative projects.

To cite this article:

Pretty, A., McPherson, P. (2017). Design dialogues. Ambiguity of "Design" within Architectural Studio. The Journal of Public Space, 2(3), Special Issue, 53-62, DOI: I0.5204/jps.v2i3.II 3

This article has been peer-reviewed and accepted for publication in The Journal of Public Space. Please see the Editorial Policies under the 'About' section of the journal website for further information.

This work is licensed under a Creative Commons Attribution - Non Commercial 4.0 International License https://creativecommons.org/licenses/by-nc/4.0/ 
The ambiguous nature of the word "design" offers up a complex dialectic dialogue for the architectural studio lecturers to impart to their students. Discussing the "design", more commonly referred to as the programme or scheme, is quite a different beast to the process or design methodologies the students use to create an architectural proposition or "design". Clarity around this notion of design as both the process, in being design-led, and also as the end result, becomes a necessary task for studio lecturers to inculcate into the student body. This paper aims to navigate through the mire/path of the design methodologies as adopted within architecture studio teaching at second year level within the Bachelor of Architectural Studies, Unitec Department of Architecture - by way of using the tried and tested notions of First Insight / Empathy, Preparation, Incubation, Illumination, Verification', with the anticipation that these are the essential tools with which to interface teaching and practice, within the context of a "live build project".

Three years' worth of case studies of large scale Interdisciplinary and collaborative "live build projects" in Christchurch in conjunction with the Festival of Transitional Architecture (FESTA) are used to demonstrate and investigate the heuristic design processes that are an integral part of a prospective architect's arsenal of skills. These case studies offered a complex window of tasks, not least that the students were designing in Auckland $1000 \mathrm{~km}$ away from the Christchurch sites, and each year posed a different set of problems and clients-related issues. Luxcity 2012 / Canterbury Tales 2013 / CityUps 2014 were the students' responses to FESTA's call to rejuvenate the city centre after the earthquakes of $20 \mathrm{I} 0$ and $20 \mathrm{II}$, and all of which were only assembled for a 24-hour period over Labour Day Weekend.

According to Professor Sam Bucolo of the University of Technology Sydney: "design should not be $a$ noun but a verb, he says. 'It's a process and quite a rigorous process.' So how do you think like a designer? 'Design thinkers' start with empathy ... 'It's a people-first approach.' Design thinking is also integrative; designers try to draw as many threads together as possible..."2

The word design etymologically is sourced from the Italian word disegno meaning to mark out. ${ }^{3}$ However this is just its noun form; its verb form comes from the Latin designare "mark out, devise, choose, designate, appoint"4. It also can be used as a "verb used with an object" and a "verb used without an object". In general terms one can assume it means to make a drawing of a work; however, it also is used as a description of "an object of the applied arts". The word Design within the Anglo-Saxon cultural norms has morphed and been substituted to describe many other things.

"A recent discourse about design terminology provides an insight into the complex world citing a wide variety of adjectives, nouns, prefixes or suffixes to the word 'Design"'. Alastair Fuad-Luke describes this in his book Design Activism, Beautiful Strangeness for a Sustainable World. ${ }^{5}$

\footnotetext{
' Lawson, Bryan. How Designers Think: The Design Process Demystified. 4th ed. Amsterdam and London: Architectural, 2006: 149.

2 Bucolo, Sam. "Why Do Some Businesses Succeed in a Challenging Environment When Others Fail? A

Different Way of Thinking May Be the Answer". \#Think UTS Business School 2014, 2014: 20-23.

${ }^{3}$ Hauffe, Thomas. Design: A Concise History Laurence King, 1998: 10.

${ }^{4}$ Harper, Douglas. "Online Etymology Dictionary". Accessed October I, 2017.

http://www.etymonline.com/index.php?term=design\&allowed_in_frame $=0$

${ }^{5}$ Fuad-Luke, Alastair. Design Activism, Beautiful Strangeness for a Sustainable World. Earthscan, 2009: I.
} 


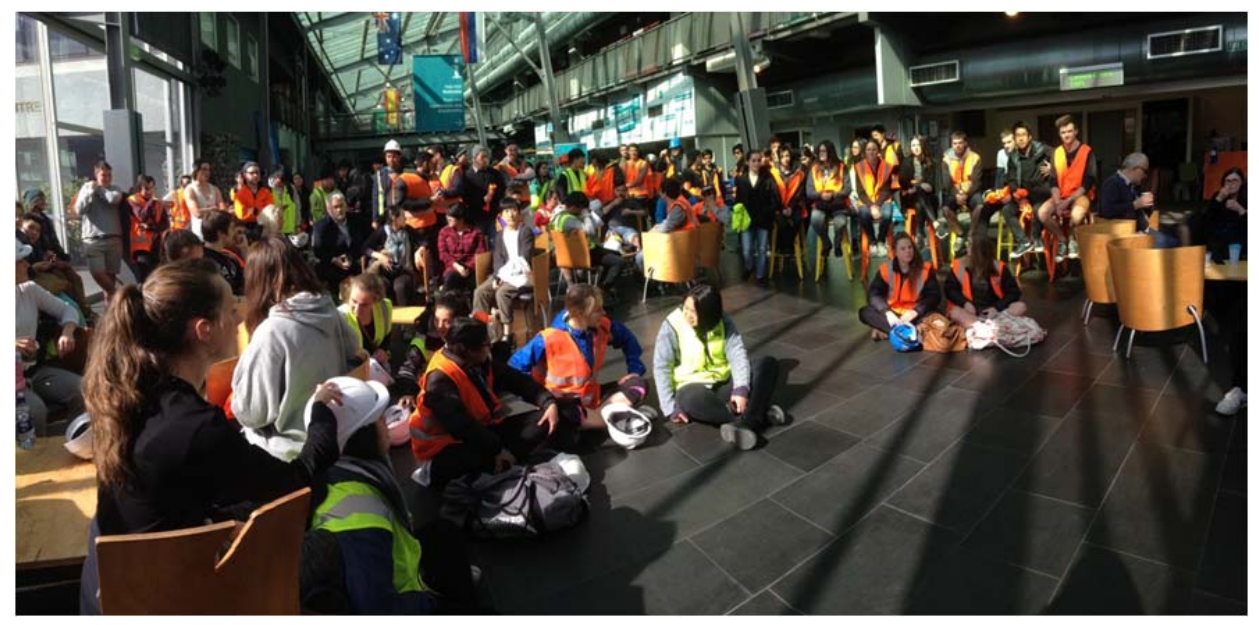

Figure I. Students going through health and safety briefings. FESTA 20I4. Photograph Annabel Pretty.

This morphing of the word to encompass so much has led to an apparent design-washing akin to the so called green-washing / eco-sustainability washing of disciplines which has become an enormous taxonomy problem for not only the designer but also for the general populace. Not only does the prefix design get affixed to nearly all the so-called disciplines in Fuad-Luke's diagram, but it confuses both the designer and the amateur to the vast array of design-led frameworks that have co-opted the word when describing the functionality of being designled. This ambiguity or plurality of the meaning of the word design often as not leads to architectural students confusing the process of design with the product of the design, or rather the architectural design proposition. This labyrinthine design paradigm will be partially unravelled by the case studies as demonstrated within this paper.

Framing the design challenge - Luxcity 2012 / Canterbury Tales 2013 / City Ups 2014

The parameters of this paper will deal with the case studies over the three-year period from 2012 to 2014, when architectural students from the second-year programme of the Bachelor of Architectural Studies (largely the entire student cohort roughly of 90 students in 20I2, $110+$ in 2014 and approximately 30 in 2013) at Unitec Institute of Technology worked with the umbrella organisations of FESTA 6 and Studio [ ] Christchurch. ${ }^{7}$ The object was to realise a number of architectural pavilions or rather light sculptural interventions within the former red zone of the aftermath of the Christchurch earthquakes of 4 September 2010 and 22 February 201 I. Largely due to the intense size of the architectural projects involved, this paper will really only seek to clarify the design methodology and process outcomes of the Unitec students; this in no way reflects on the other architecture schools or staff but is meant to address the plurality of the nature of the process from within the authors' teaching dimensions.

\footnotetext{
${ }^{6}$ FESTA. "Festa - Festival of Transitional Architecture", Te Pūtahi - Christchurch Centre for Architecture and City-making. Accessed October I, 2017. http://festa.org.nz.

${ }^{7}$ Christchurch, Studio [ ]. Accessed October I, 2017. https://studiochch.wordpress.com.
} 


\section{Collaborative Design - Framework-Stage I}

The 2012 commencement of the project was pitched to the entire student cohort, led by all lecturers, typically six staff in total. The students were assigned into groups of roughly five with the expectation that they should research other architectural light pavilions and present their findings to a joint audience of Unitec Lecturer's and students plus the students and staff of University of Auckland, alongside former Christchurch Polytechnic Institute of Technology (CPIT) now Ara Insititute of Canterbury and Auckland University of Technology (AUT). An expert panel of external academic and professional practitioners of architecture would judge the fabrication of these transitional architectural pavilions as:

The upshot of this was the collaboration necessary between a variety of Architecture schools, to create a design critique for 18-20 projects each of which only 6 would move forward onto the second round of being matched with a client and moving to the pre-fabrication and council permissions. This was a huge learning experience for the students having to give a verbal presentation to students within other universities and to understand the scope of the variety of projects. The projects were ranked according to I) Design potential; was it feasible from a budgetary and from a locational aspect bearing in mind that the sites which the students designed for were a constantly changing feast due to buildings being demolished, and the Red zone being reduced in size. 2) Did it encompass the elements of a "city of light"? Both in a literal sense and in a pragmatic sense as the predominant number of the students were designing, being based in Auckland for shipping to the site in Christchurch $1082 \mathrm{~km}$ distance. 3) Was it great transitional Architecture? ${ }^{8}$

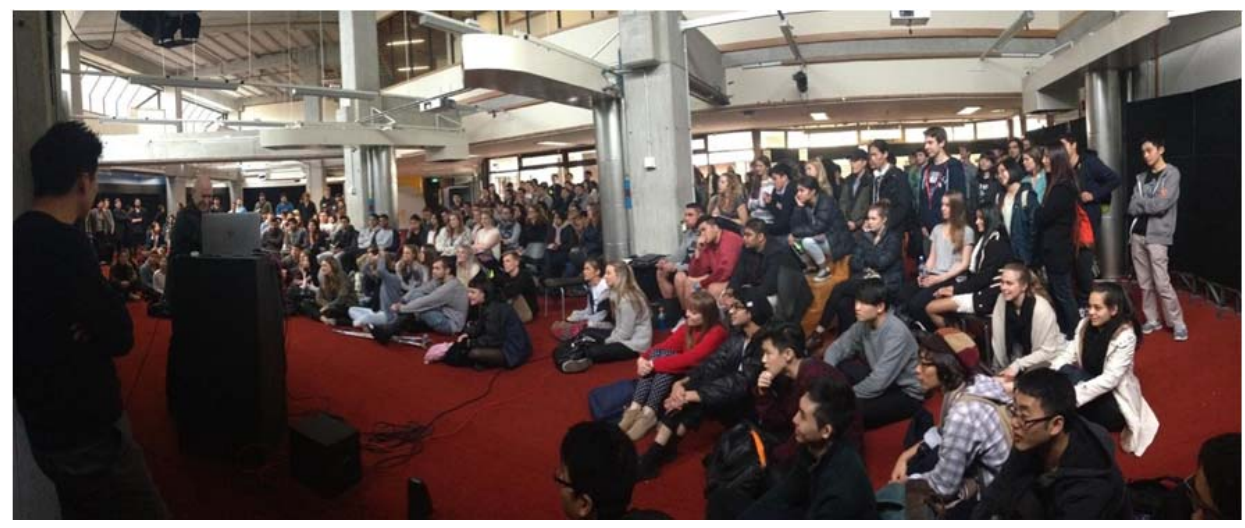

Figure 2. Presentation of all student projects, at University of Auckland. Photograph Annabel Pretty.

Designed by Committee - "It is a commonly held view that good design results when projects are driven by an autocratic leader and bad design results when projects are driven by democratized groups." 9

Students typically moved through the five stages of design methodologies, seeking research, preparing design solutions, incubating their ideas; however, once they had pitched their ideas to an external panel of professional architects the next phase of the design problem occurred.

\footnotetext{
${ }^{8}$ Pretty, Annabel. "Incubating + Scaling - Transitional Large Fabrication Architectural Design Propositions in a Post-Earthquake Environment”, Paper presented at The Virtuous Circle: Design Culture and Experimentation Milan, 20I5: 121 .

${ }^{9}$ Grossman, Wendy. "Designed for Life." New Scientist 76 (5 October 2002): 236.
} 
The six projects, which progressed to the next phase, meant for a complex blend of personalities, cultures and expectations. This led to a convoluted iteration of the design process as students worked in their groups of five for a period of two weeks following the Empathy or First Insight, Preparation, Incubation, Illumination, Verification theoretical model. Obviously, some groups navigated the tangled, intricate interpersonal relations between students, more fully than others, to realise a potential design outcome. The resultant project was ranked by the external panel as to determine those who should progress to the second stage.

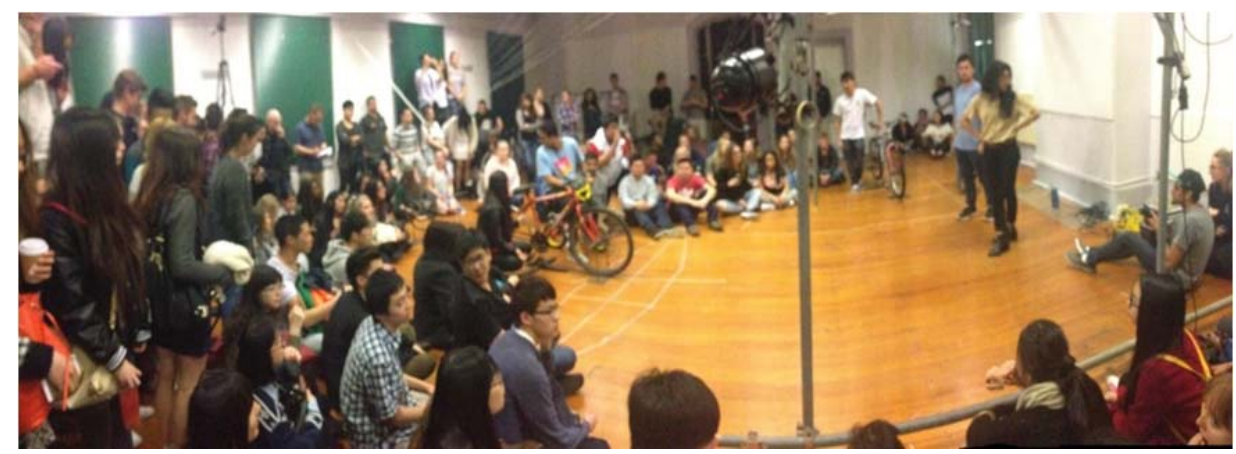

Figure 3. Presentation of all student projects, at Unitec Institute of Technology. Photograph Annabel Pretty.

Collaborative Design - Framework- Stage 2; Re-Framing the Design Methodologies

The numerous component design problems within the brief of at least 16 identifiable components (see diagram figure 4) which were impactful on the incubation of the design, meant that once the groups of five students had merged into a group of between 18-20 students there was a re-framing of their ideas; to blend, merge and reassess the relevance of the ideas in order to then re-frame the solution meant for a complex process.

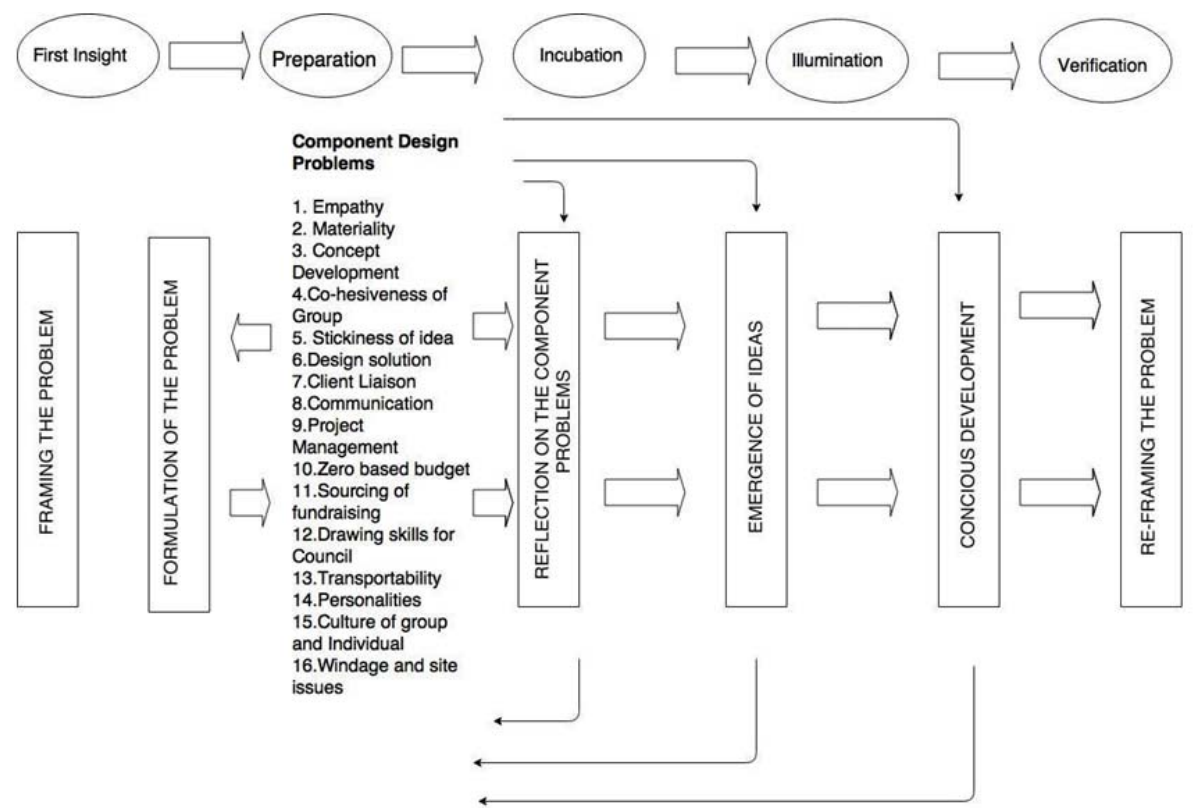

Figure 4. Annabel Pretty interpretation of Kneller's creative process as applied to case studies within this paper. 
Needless to say, the reiteration of the concept of Ockham's Razor became a necessity. Ockham's Razor states, "given a choice between functionally equivalent designs, the simplest design should be selected."'0 Ockham's Razor (Latin, ex parsimoniae, which means 'law of parsimony') asserts that simplicity is preferred to complexity in design, exemplified by the notion of "form follows function" variously attributed to I $8^{\text {th }}$ century Jesuit Monk Carlo Lodoli and latterly Horatio Greenough and Louis Sullivan." Though not intended truly for design the concept has been appropriated into the vast array of schematics for working with design methodology. Whereas some groups had a "lead group" that often as not was the design concept, groups were merged together by the tutors involved in order to ensure that at least 16 or so identifiable problems were in different proportions for each group (see figure 4).

\section{Case Study - Archrobatics}

To navigate the design process and build a sense of community within a group and to 'glue' the various design methodologies and cultures and knowledge base was a knotty convoluted process. This reframing of the idea or concept was typified by a group in 2012. Team Archrobatics had a complex idea to include immense helium filled balls (two metres or so in diameter) with some of the concepts of previous groups, which included large strung up objects and a complex pulley system. This group went through an intensive reframing led by a number of the lecturers in a bid to work through their ideas rather than the steadfast attempt to hold forth with all the ideas from the five groups. The culmination of this was a need to refine, redefine and simplify in fact to exemplify the concept of Horror Vacui - the Latin expression meaning the "fear of emptiness" - to fill empty spaces with information or objects over leaving places blank or empty.
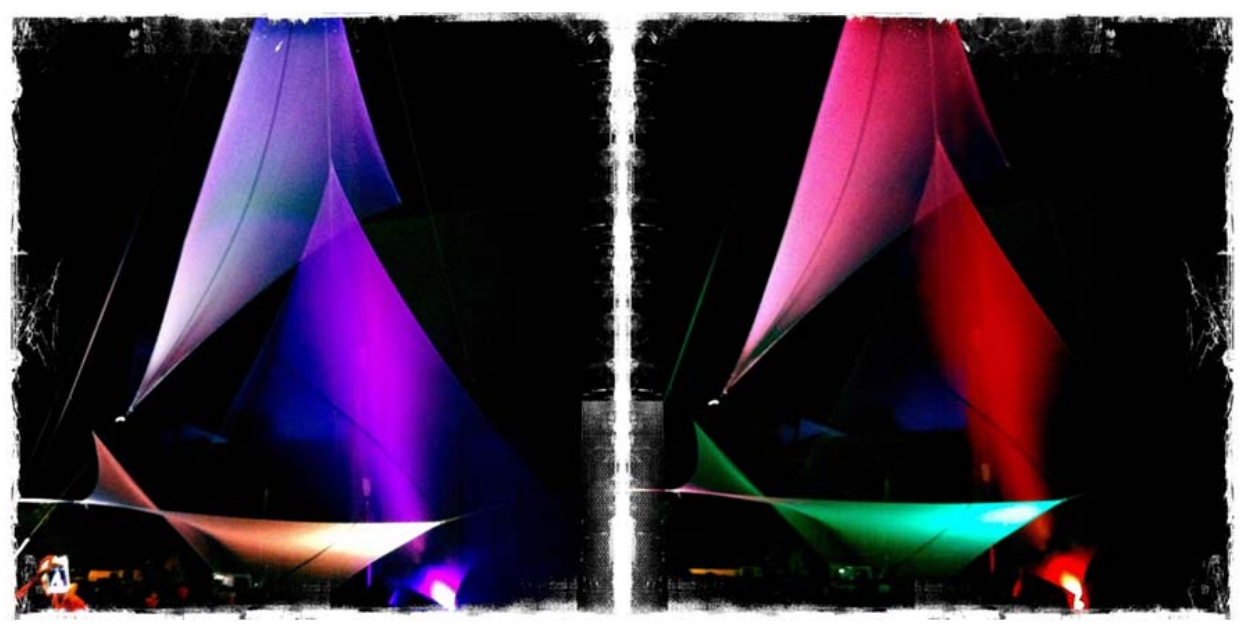

Figure 5 (on the left). Team Archrobatics. Photographs Annabel Pretty.

Lecturers spent vast quantities of time with these students insisting on a clarity of concept and simplicity of ideas. This eventually occurred moments before drawings were needed for council permits. Using the simple idea of using the bird netting normally used to drape around the vineyards, the core concept was a lightweight material that had certain

\footnotetext{
${ }^{10}$ Thorburn, W. M. “The Myth of Occam's Razor”, Mind, 27 (1918): 345-53.

" Lidwell, William, Kritina Holden, and Jill Butler. Universal Principles of Design. Rockport Publishers, 2003 : 106.
}

58 | The Journal of Public Space, 2(3), 2017 | Special Issue | ISSN 2206-9658

(C) Queensland University of Technology 
stretchiness on the diagonal, which meant that the netting was cut into a sort of scalene triangle that under three points of pressure made for an impactful solution of concept and was in fact, in 2012, one of the most commented about "light pavilions" due to its simplicity of structure.
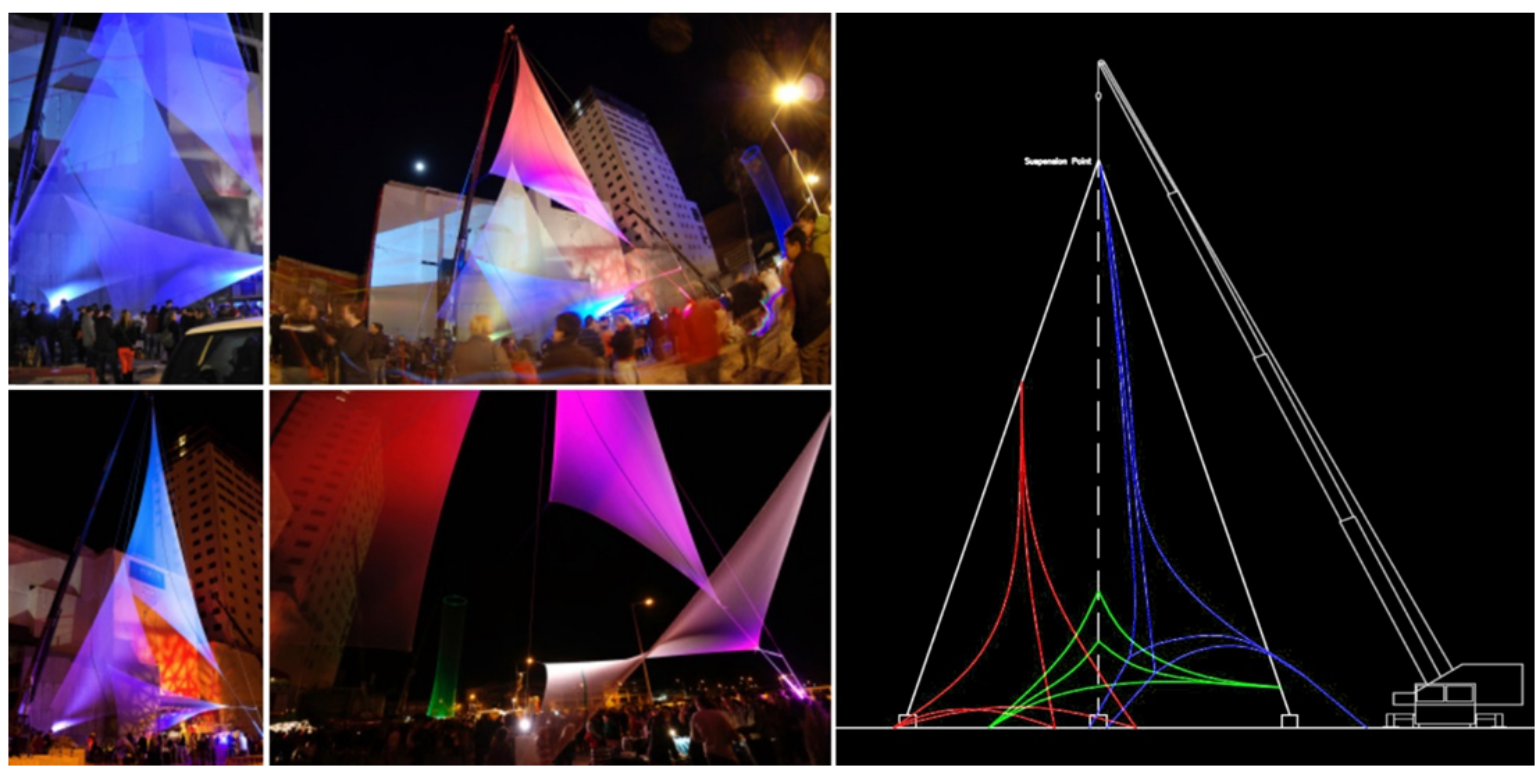

Figure 6 (on the left). Team Archrobatics. Photographs Annabel Pretty.

Figure 7 (on the right). Team Archrobatics, Health and Safety Plan.

Case Study 2013 - Illuminate

2013 saw a slight variation of the way in which the project was run in that the whole cohort of students was not invited to participate so that the final 25-28 or so students blended much more smoothly than in 2012 , such that it was easier to manage even though all the design issues were still the same. For example, windage became a huge factor in this project; one of the most successful projects "Illuminate" was by a group of students who quickly realised that the LED lights could be sourced cheaply and once taken out of their "housings" were quite easily able to be used in other ways. The concept was to make a modular hexagon repeating lightweight, flexible structure that could be built up creating a dense cloud-like structure that also had the notion of both transparency and translucency. The hexagon structures were created from variously coloured drinking straws that lit up from the LED light source in the centre of the module; since the hexagon was expanded in the middle section it became rather like the concept of quilting to attach the modules together. Much testing to ensure they would endure the pulling and grabbing from the crowd meant that a support system of small sticks was necessary within the drinking straws to reduce the fully flexible system. Ironically the group found that the most practical and easily sourced same-size small sticks turned out to be kebab sticks, which caused quite some issues on their health and safety report as to the ability to ensure that they were all removed safely from the site at the end of the night. Probably the main reason that this was so successful on the day was the ease with which the modular system could be changed due to site specifications (site specification changed regularly). The capacity to raise and lower the structure via four scissor lifts, and the ability to make the structure on site, albeit the students had created the hexagon modules in Auckland and transported them down to Christchurch via excess baggage on the plane, meant for a 
very flexible enduring structure. They were able to connect them to make larger modules in the days before the Labour Day opening, which meant for the efficient use of time. The simple structure once repeated, determined for an impactful final resolution of design (see figures 5-II).

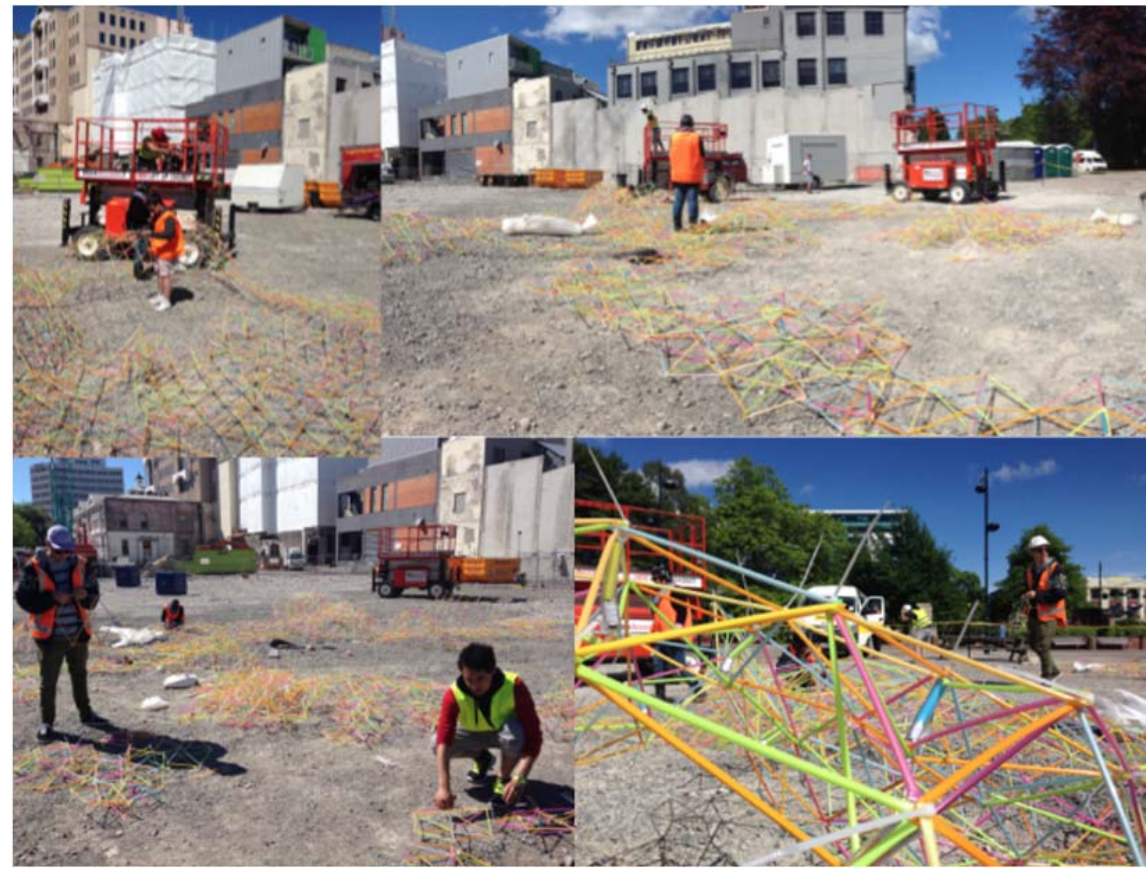

Figure 8. Team Illuminate. Photograph Annabel Pretty plus Unitec Architecture Department - Asylum 2013.

\section{4 - Case study Aurora}

Aurora was the culmination of three groups pitching their concept to move forward for CityUps 2014: Aurora (http://auroralightsnz.wordpress.com), Inflate (http://inflatechristchurch2014.wordpress.com) and Puffed Up+ (http://cityups2014.tumblr.com). Inflate dealt with the concept of using car batteries to inflate and deflate a large balloon-like structure; Puffed Up+ dealt with the concept of recycling plastic bags and creating a sort of structure looking not un-like a bunch of hanging grapes; and Aurora's genesis was from using the childhood toy "slinky" (pre-compressed helical springs), trying to figure out how to scale these up without losing the concept of interactivity. Once the three groups of five students merged, they needed to work through the design processes to determine the most likely design concept that would work, and once they had identified that flexible ducting (air-condition unit ducting) had similar properties to the slinky, the design could move forward. The problem for this group became that once they were one of the teams to have these large $12 \mathrm{~m} \times 10 \mathrm{~m}$ proscenium frames, a system of hanging the ducting became an architectural engineering problem. However, this was resolved by using scaffolding to bisect the large-scale frame to hang the tubing free from the structure. Aurora became one of the most cogent designs of the night due to the interactive nature of the design, with the ability for the audience to interact with one another via "talking down the tube" just like a childhood toy. 

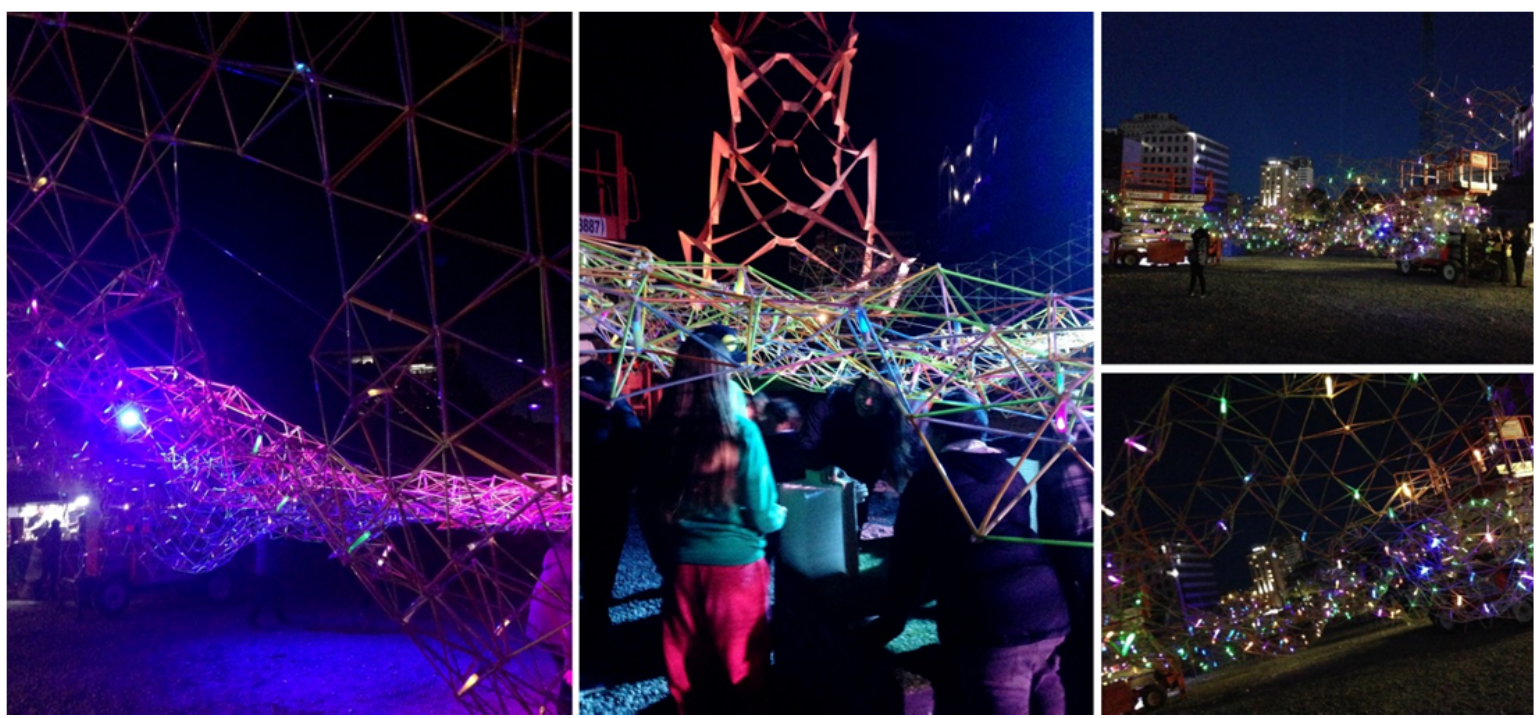

Figure 9 Team Illuminate. Photograph Annabel Pretty plus Unitec Architecture Department - Asylum 2013.

\section{Drawing Design Conclusions}

In drawing conclusions from this complex dialectic dialogue, of the notion of ambiguity of "Design" within Architectural Studio, one must be cognisant that:

Everything that is absorbed and registered in your mind adds to the collection of ideas stored in the memory: a sort of library that you can consult whenever a problem arises. So, essentially, the more you have seen, experience and absorbed, the more points of reference you will have to help you decide which direction to take: your frame of reference expands. (Lawson p. 156, quoting Hertzberger 1991) 12

The manifestation and embodiment of the case studies by using these design methodologies via team collaboration and having an outcome that was then variously disseminated to a vast audience (30,000 in 2012 and 10,000 in each of 2013 and 2014) has led these students to describe, interpret and critical analysis their design thinking. Positively demonstrating the feedback loop as illustrated in figure 5 with the application of the design thinking overlaid within an architectural context.

Designing is not a linear experience, in which you have an idea, put it down on paper, then carry it out and that's that. Rather it is a circular process: your idea is drawn up, tried, out, reconsidered, and reworked, coming back again and again to the same point.

(Brawne p. 78, quoting Piano, 1997, p. 18)13.

Over the preceding three years of these projects/case studies, one of the defining conclusions that must be drawn is the impactful way in which working in an interdisciplinary and collaborative team, creating a small defined community within themselves, creating connections to other communities of practice, other institutes, public retail partners within the greater community of Christchurch has led to a greater understanding of the design

\footnotetext{
${ }^{12}$ Lawson, Bryan. How Designers Think: The Design Process Demystified. 4th ed. Amsterdam and London: Elsevier, Architectural Press, 2006: 156.

${ }^{13}$ Brawne, Michael. Architectural Thought: The Design Process and the Expectant Eye. Amsterdam and Boston: Elsevier, Architectural Press, 2005.
} 
process, and design research. The various student groups constantly had to frame and reframe the design problem so as to interpret the process for strategically identifying solutions to their many and varied problems both of design and of the design, both verb and noun, and tease out the many various notions of design, and its complex ambiguity, within the context of interdisciplinary and collaborative live build projects.
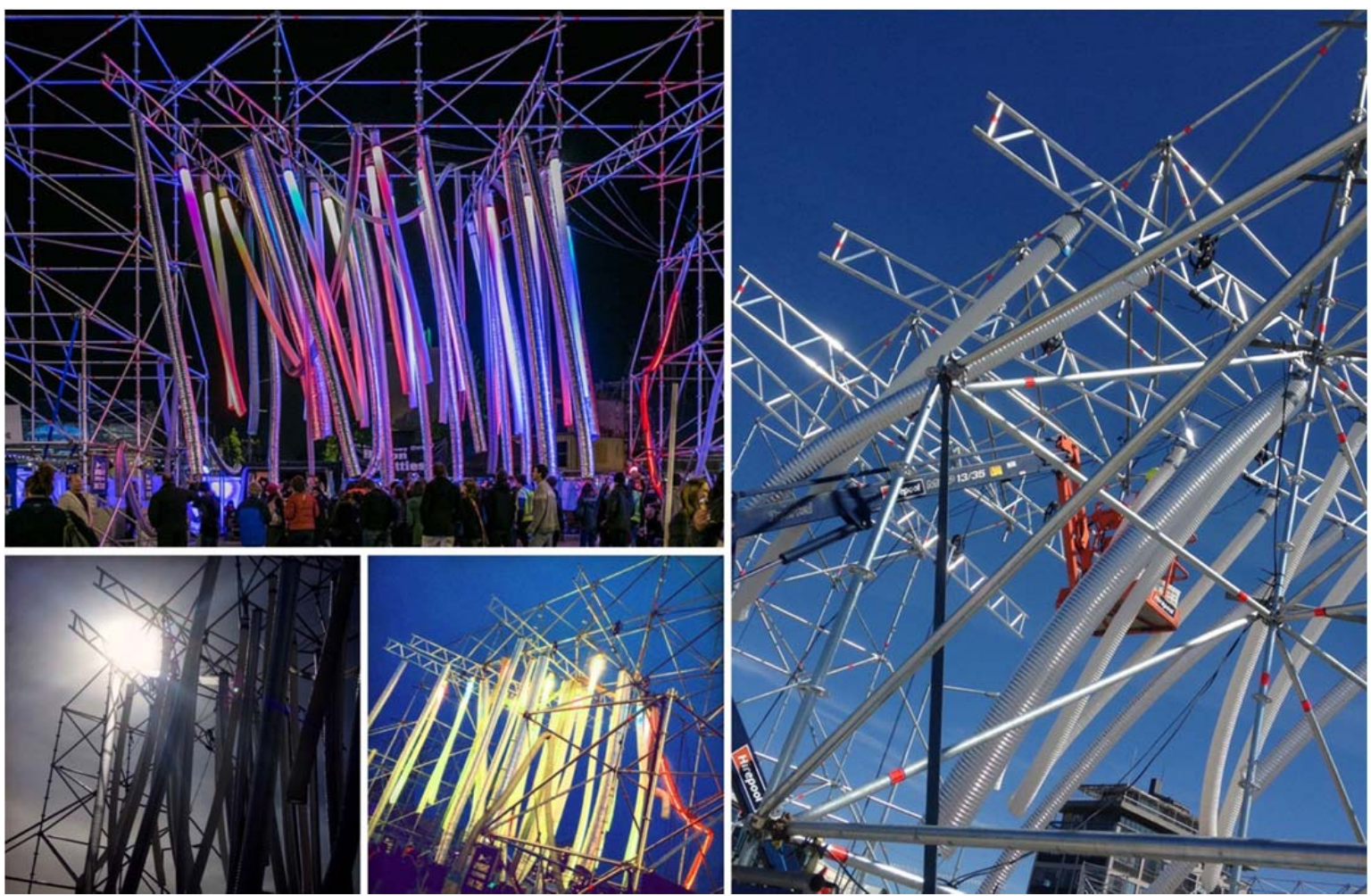

Annabel Pretty.

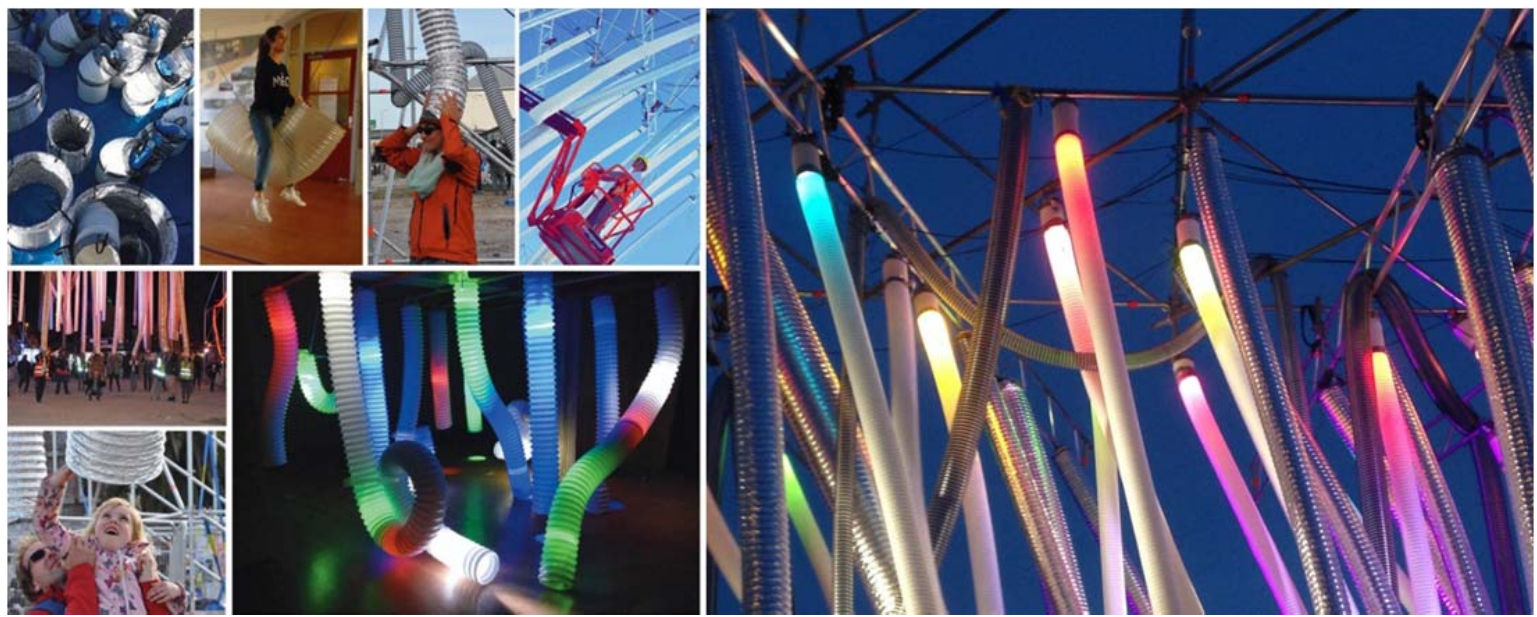

Figure II. Team Aurora. Photograph Annabel Pretty.

62 | The Journal of Public Space, 2(3), 2017 | Special Issue | ISSN 2206-9658

(c) Queensland University of Technology 